\title{
Aumentando a eficácia e a eficiência da avaliação do ensino superior: a relação entre o Enem e o Enade
}

\author{
ANA CAROLINA PEREIRA ZOGHBI* \\ BRUNO TEODORO OLIVA** \\ GABRIELA MIRANDA MORICONI***
}

\begin{abstract}
RESUMO
A aplicação do Exame Nacional de Desempenho dos Estudantes (Enade) para alunos ingressantes trouxe um significativo avanço para a avaliação do ensino superior no país: a possibilidade do cálculo de uma medida de valor agregado do curso, o Indicador de Diferença entre os Desempenhos Esperado e Observado (IDD). Uma proposta para a melhoria da avaliação do ensino superior brasileiro, porém, seria a utilização dos resultados do Exame Nacional do Ensino Médio (Enem) como baseline para o cálculo do IDD. Haveria um aumento da eficiência devido à não aplicação do Enade para alunos ingressantes, reduzindo custos. Já o aumento da eficácia se daria em razáo da obtenção de um baseline melhor, em virtude dos fortes incentivos para fazer a prova. Neste estudo, analisou-se a possibilidade de se utilizar os resultados do Enem, como alternativa aos resultados do Enade dos ingressantes, para o cálculo

* Doutoranda em Política e Economia do Setor Público da EAESP/FGV e Pesquisadora do CEPESP/FGV (Centro de Política e Economia do Setor Público) (zoghbi80@yahoo.com.br). ** Doutorando em Economia pela EESP/FGV (olivabt@yahoo.com.br).

*** Doutoranda em Administração Pública e Governo da EAESP/FGV e Coordenadora-Geral de Instrumentos e Medidas Educacionais do Inep (gabriela.moriconi@inep.gov.br).
\end{abstract}


do IDD dos cursos. Ao calcularmos um novo IDD, substituindo a nota do Enade dos alunos ingressantes pela nota do Enem desses alunos, obtivemos correlaçóes entre esse novo IDD e o IDD calculado tradicionalmente, de cerca de 0,75 , indicando que não haveria uma mudança muito significativa na ordenação das notas dos indivíduos, o que viabilizaria essa substituição. Palavras-chave: Avaliação da educação, Ensino superior, Indicador de diferença entre os desempenhos observado e esperado (IDD).

\section{RESUMEN}

La aplicación del Examen Nacional de Desempeño de los Estudiantes (Enade) para los alumnos que ingresan implicó un avance significativo para la evaluación de la enseñanza superior del país con la posibilidad de calcular una medida de valor agregado del curso, el Indicador de la Diferencia entre los Desempeńos Esperado y lo Observado (IDD). Sin embargo, una propuesta para mejorar la evaluación de la enseñanza superior brasileña sería la utilización de los resultados del Examen Nacional de Enseñanza Media (Enem) como línea de base para el cálculo del IDD. Habría un aumento de la eficiencia debido a que no se aplicaría el Enade a los alumnos que ingresan, reduciendo así los costos. El aumento de la eficacia se daría en función de la obtención de una línea de base mejor, debido al fuerte incentivo para hacer la prueba. En este estudio, se analizó la posibilidad de utilizar los resultados del Enem, como alternativa a los resultados del Enade de los alumnos que ingresan, para el cálculo del IDD de los cursos. Al calcular un nuevo IDD, que sustituya la nota del Enade de los alumnos que ingresan por la nota del Enem de los mismos, obtuvimos correlaciones entre ese nuevo IDD y el IDD calculado tradicionalmente, de aproximadamente 0,75 . Esto indica que no habría un cambio muy significativo en la ordenación de las notas de los individuos, lo que viabilizaría esa sustitución.

Palabras clave: Evaluación de la educación, Enseñanaza superior, Indicador de la diferencia entre los desempeños observado y esperado (IDD).

\section{ABSTRACT}

Administering the National Assessment Examination of Student Performance (Enade) to new students meant a significant advance in the evaluation of higher education in the country: the possibility to calculate a measure of added value of the course, the Indicator of the Difference between Expected and Observed Performances (IDD). A proposal for improving the assessment of higher education in Brazil, however, would be to use the results of the National Secondary Education Examination (Enem) as a baseline for calculating the IDD. There would be an increase in efficiency due to the non-application of Enade to freshmen, thus reducing costs. In turn, the increase in efficiency would be due to obtaining a better baseline, because of strong incentives to take the examination. In this study, we analyzed the possibility of using the Enem results as an alternative to the Enade results of freshmen in order to calculate the IDD of the courses. When a new IDD was calculated, replacing the freshmen's Enade grade with the Enem grade of these students, we found correlations between this new IDD and the traditionally calculated IDD, of about 0.75 , indicating that there would not be a very significant change in the ranking of individuals grades, which would mean that this substitution is quite viable.

Keywords: Education assessment, Higher education, Indicator of the difference between observed and expected performances (IDD). 


\section{INTRODUÇÃO}

As avaliaçóes educacionais em larga escala, uma realidade presente em diversas partes do mundo desde a década de 70 , vêm crescendo no Brasil nos últimos anos, tanto em quantidade como em qualidade. O Sistema Nacional de Avaliação da Educação Básica (Saeb) foi a primeira iniciativa brasileira, em escala nacional, para se conhecer o sistema educacional brasileiro em profundidade, o qual começou a ser desenvolvido no final dos anos 80 e foi aplicado pela primeira vez em 1990 .

O uso de avaliaçóes em larga escala para o ensino superior no Brasil, por sua vez, é iniciado em 1996, com a criação do Exame Nacional de Cursos, mais conhecido como Provão. É interessante observar que, apesar da crescente preocupaçáo com a avaliação do ensino superior, de acordo com Verhine, Dantas e Soares (2006), apenas o Brasil adota um exame nacional de cunho obrigatório para o ensino superior - dentre aproximadamente 40 países em que os autores encontraram literatura disponível sobre o tema.

O Provão, exame universal e obrigatório, era aplicado anualmente aos alunos dos cursos de graduação selecionados - iniciou-se em 1996 com administração, direito e engenharia civil, e foi sendo expandido até avaliar 26 áreas em 2003, último ano de aplicaçáo. Participavam do exame somente os alunos concluintes dos referidos cursos, o que permitia que o Instituto Nacional de Estudos e Pesquisas Anísio Teixeira (Inep) calculasse e divulgasse um conceito referente à qualidade do curso. Foi a primeira vez que se teve uma medida objetiva da qualidade média dos alunos egressos desses cursos, auxiliando empregadores e potenciais estudantes em suas escolhas. Adicionalmente, pretende-se que a divulgação desses resultados às instituiçóes de ensino auxilie e incentive o processo de melhoria do ensino. Hanushek e Raymond (2004), por exemplo, encontram resultados empíricos que indicam que estados americanos que têm sistemas de avaliação do ensino básico com base na accountability obtiveram melhores desempenhos educacionais do que os estados sem avaliação. A análise de Rezende (2008) do Provão como instrumento de accountability indica impactos diferenciados sobre a atuação das instituiçóes de ensino superior de acordo com seu tipo de organização - por exemplo, trata-se de universidade ou outro tipo de instituição.

No entanto, embora a qualidade média do aluno egresso seja uma medida extremamente importante, não se pode dizer que é um indicador direto do trabalho da instituição. Isto porque um curso que recebe alunos com formação anterior deficiente pode realizar um ótimo trabalho e, ainda assim, não ter seus ex-alunos entre aqueles com as melhores notas em um exame como o Provão. Do mesmo modo, um curso pode 
receber alunos com excelente formaçáo anterior e, mesmo sem muito esforço, ter bons resultados finais, comparativamente.

Fato é que, tanto para os gestores das instituições de ensino como para os órgãos reguladores e toda a sociedade, é importante saber o valor agregado desse curso, ou seja, quanto o curso contribuiu para a formação dos alunos.

Nesse sentido, a substituição do Provão pelo Exame Nacional de Avaliação do Desempenho dos Estudantes (Enade), a partir de 2004, trouxe um significativo avanço para a avaliação do ensino superior no país: a possibilidade do cálculo de uma medida de valor agregado do curso, o Indicador de Diferença entre os Desempenhos Esperado e Observado (IDD). Ao exigir que alunos ingressantes dos cursos de ensino superior das áreas avaliadas também realizem o exame, o Inep garantiu a existência de um baseline, isto é, uma medida de comparação da formação inicial dos alunos.

Contudo, ainda existe o risco de uma distorção relacionada à falta de incentivos que os estudantes ingressantes têm para se esforçarem na realização da prova do Enade. Tal distorção será mais acentuada quanto maior for a heterogeneidade do esforço dos alunos ingressantes entre as escolas. Por exemplo, se uma escola que agrega mais conhecimento tiver ingressantes mais esforçados que aquelas que agregam menos conhecimento, o Enade subestimará o verdadeiro valor médio agregado pelo ensino superior brasileiro. Adicionalmente, ainda é possível que instituiçóes de ensino superior incentivem seus alunos ingressantes a não se esforçarem nessa prova, na tentativa de aumentar o valor agregado calculado pelo IDD, numa prática de gaming.

Assim, uma proposta para a melhoria da avaliação do ensino superior brasileiro, em termos de eficiência e eficácia, seria a utilização dos resultados do Exame Nacional do Ensino Médio (Enem) como baseline para o cálculo do IDD - a medida de valor agregado calculada atualmente. $\mathrm{O}$ aumento da eficiência se daria por motivos óbvios: a redução de custos devido à não aplicação do Enade para alunos ingressantes no ensino superior. Já o aumento da eficácia se daria em razão da obtenção de um baseline melhor - um indicador de melhor qualidade sobre a formação anterior dos alunos ingressantes. Isto se deve ao fato de que o aluno tem forte incentivo para fazer a prova, uma vez que o seu desempenho já é critério para o processo seletivo em cerca de 500 universidades, para programas que concedem bolsas de estudos em especial, o ProUni - e deverá ter seu uso expandido com a proposta de uso do Enem, em novo formato, para substituir o vestibular das universidades federais. Dados do Inep mostram inclusive que o número de avaliados pelo Enem nos últimos

48 - Est. Aval. Educ., São Paulo, v. 21, n. 45, p. 45-66, jan./abr. 2010 
anos se aproximou do total do universo de alunos que concluíram o ensino médio e buscam ingressar em uma universidade.

O objetivo deste estudo é, portanto, realizar uma análise da possibilidade de se utilizar os resultados do Enem como alternativa aos resultados do Enade dos ingressantes para o cálculo do IDD dos cursos - indicador de valor agregado utilizado atualmente. Para tanto, calculamos um novo IDD para o ano de 2006, substituindo a nota do Enade dos alunos ingressantes pela nota do Enem 2005 desses mesmos alunos, e analisamos as correlaçóes entre esse novo IDD e o IDD calculado tradicionalmente, tendo a nota do Enade dos ingressantes como baseline. Com esta análise, pretende-se agregar mais informaçóes ao estudo dos resultados das avaliaçóes educacionais realizadas no país, oferecendo maiores subsídios à revisão das políticas de avaliaçáo do ensino, permitindo a proposição de melhorias em termos de eficiência e eficácia na realização da avaliação educacional no Brasil.

\section{AVALIAÇÕES EDUCACIONAIS: ENEM E ENADE}

Dados os objetivos deste estudo, trabalharemos com o Enem e o Enade, avaliaçóes realizadas pelo Inep e descritas a seguir.

\section{Enem}

O Exame Nacional do Ensino Médio (Enem) é um exame individual, de caráter voluntário, oferecido anualmente aos estudantes que estáo concluindo ou que já concluíram o ensino médio em anos anteriores.

O principal objetivo do Enem é avaliar o desempenho do aluno ao término da escolaridade básica, para aferir desenvolvimento de competências fundamentais ao exercício pleno da cidadania. Desde a sua concepção, porém, o exame foi pensado também como modalidade alternativa ou complementar aos exames de acesso aos cursos profissionalizantes pós-médio e ao ensino superior.

Apesar de voluntário, o Enem caminha para a universalização entre os estudantes que terminam o ensino médio, pois diversas instituições de ensino superior (IES) têm passado a utilizar os resultados do Enem como componente dos seus processos seletivos. Além disso, essa universalização do exame tem sido promovida pela sua participaçáo em programas governamentais de acesso ao ensino superior, como o ProUni, por exemplo, que utiliza os resultados do Enem como pré-requisito para a distribuição de bolsas de estudo em instituiçóes privadas de ensino superior. 
Atualmente, a prova do Enem é interdisciplinar e contextualizada. Nela, busca-se colocar o estudante diante de situaçóes-problema e medir não apenas se ele conhece os conceitos, mas se sabe aplicá-los. A prova é composta de uma parte objetiva com 63 questôes e de uma redação. Trabalha com uma escala clássica de 0 a 100 para a atribuição da nota final, tanto na parte objetiva quanto na redação.

Recentemente, o Ministério da Educação divulgou uma proposta de que o Enem seja utilizado pelas universidades federais para subsidiar a seleção de seus alunos, mais especificamente permitindo um processo unificado para todas aquelas que aderirem ao sistema. Em termos da prova, o Inep propóe uma reestruturação metodológica do exame, de forma a aproximar o exame das Diretrizes Curriculares Nacionais e dos currículos praticados nas escolas, exigindo mais conhecimentos em termos de conteúdo, mas sem abandonar o modelo de avaliaçáo centrado nas competências e habilidades. Segundo o MEC (Brasil, 2009), serão aproximadamente 50 questóes para cada um dos quatro testes: 1) Linguagens, Códigos e suas Tecnologias; 2) Ciências Humanas e suas Tecnologias; 3) Ciências da Natureza e suas Tecnologias; e 4) Matemática e suas Tecnologias.

Com essas alteraçóes, acredita-se que o Enem passará a ser um instrumento melhor em termos da discriminação dos conhecimentos e habilidades dos alunos, e ainda deverá ser realizado por um número ainda maior de indivíduos caso realmente aumente o número de instituiçôes a utilizá-lo como parte de seu processo seletivo.

\section{Enade}

O Exame Nacional de Desempenho dos Estudantes (Enade) é aplicado aos alunos ingressantes e concluintes em cursos de graduação, de áreas definidas pelo MEC anualmente, sendo que a periodicidade de aplicação do Enade, a cada área, é trienal.

O objetivo do Enade é avaliar o desempenho dos estudantes com relação aos conteúdos programáticos previstos nas diretrizes curriculares dos cursos de graduação, o desenvolvimento de competências e habilidades necessárias ao aprofundamento da formação geral e profissional, e o nível de atualização dos estudantes com relaçáo à realidade brasileira e mundial. O Exame é parte integrante do Sistema Nacional de Avaliação da Educação Superior (Sinaes), juntamente com a avaliação institucional e a avaliação dos cursos de graduação.

A prova é composta de 40 questôes, sendo 10 da parte de formação geral, comum aos estudantes de todos os cursos que realizam o Enade naquele ano, e 30 de

50 - Est. Aval. Educ., São Paulo, v. 21, n. 45, p. 45-66, jan./abr. 2010 
um componente específico, relativo àquele curso de graduação, contendo, as duas partes, questóes discursivas e de múltipla escolha.

O Enade é realizado por amostragem. O Inep constitui a amostra dos participantes a partir da inscrição, na própria instituição de ensino superior dos alunos habilitados a fazer a prova. Ele é componente curricular obrigatório dos cursos de graduação, sendo o registro de participação condição indispensável para a emissão do histórico escolar, independentemente de o estudante ter sido selecionado ou náo no processo de amostragem do Inep.

Já o conceito do curso é calculado pela média ponderada da nota padronizada dos concluintes no componente específico, da nota padronizada dos ingressantes no componente específico e da nota padronizada em formaçáo geral (concluintes e ingressantes), possuindo estas, respectivamente, os seguintes pesos: $60 \%, 15 \%$ e $25 \%$. Assim, a parte referente ao componente específico contribui com $75 \%$ da nota final do curso, enquanto a parte de formaçáo geral contribui com $25 \%$. O conceito é apresentado em cinco categorias (1 a 5), sendo que 1 é o resultado mais baixo e 5 é o melhor resultado possível, na área.

O Enade possibilita, também, calcular uma medida direta da contribuição da escola para a formação acadêmica de seus estudantes, o Indicador de Diferença entre os Desempenhos Observado e Esperado (IDD), o qual já foi citado e cujo cálculo será descrito de forma detalhada mais adiante.

O Conceito Enade, juntamente com o IDD, são divulgados amplamente pelos meios de comunicação e são alguns dos instrumentos de accountability existentes atualmente em relação ao ensino superior. Adicionalmente, as notas no Enade e os valores calculados para o IDD de cada curso são combinados a indicadores de insumo referentes a docentes, infraestrutura e fatores pedagógicos dos cursos para compor o Conceito Preliminar de Curso (CPC). Esse indicador tem a função de orientar e racionalizar as avaliaçóes in loco. Se maior que 2, o curso pode dispensar a visita e, assim, o CPC torna-se automaticamente o Conceito de Curso. Para os cursos visitados (por solicitação ou por ter o CPC inferior a 3), o Conceito de Curso é dado pelos avaliadores. Mas, caso divirja do CPC, é necessário uma justificação sólida dos motivos. Com isso, espera-se eliminar a aparente contradição entre indicadores objetivos e os da avaliação in loco. Assim, o CPC é um indicador intermediário que viabiliza e dá consistência ao Conceito de Curso. A vantagem da avaliação in loco é poder observar características específicas dos cursos que são impossíveis de se detectar com indicadores padronizados, e assim completar os ciclos de avaliação dos cursos previstos no Sinaes. 


\section{ANÁLISE EMPÍRICA: AVALIÇÃO DA CAPACIDADE PREDITIVA DO ENEM EM RELAÇÃO AO ENADE}

Passaremos ao estudo da viabilidade de se utilizar a nota do Enem com os mesmos objetivos em que são empregadas as notas dos ingressantes do Enade, o que indicaria a possibilidade de substituir a primeira pela segunda, aumentando dessa forma a eficácia do processo avaliativo, como já apontado.

A principal aplicação da nota do ingressante do Enade é o cálculo anual do IDD. Assim, a nossa análise dessa potencial capacidade preditiva será realizada por meio do recálculo do IDD 2006, substituindo a nota do Enade dos alunos ingressantes pela nota do Enem 2005 desses mesmos alunos. Os resultados dessa pesquisa permitirão ao MEC avaliar, de forma mais crítica, a importância da aplicação da prova do Enade aos alunos ingressantes nos cursos avaliados.

A fim de esclarecer a metodologia adotada nessa primeira análise, segue uma breve descrição do IDD, baseada na nota técnica divulgada pelo Inep (2007).

\section{O cálculo do IDD original}

Um aspecto muito importante que deve ser considerado ao avaliar a qualidade de um curso é o seu "valor agregado" ao aluno. Este conceito diz respeito a quanto o curso contribuiu para o desenvolvimento das habilidades dos estudantes.

Existe uma série de problemas que precisam ser contornados para que se obtenha uma medida adequada de valor agregado. Notadamente, o fato de o perfil dos alunos ingressantes ser muito desigual entre as diferentes instituiçôes influencia sobremaneira o resultado dos concluintes em exames de aptidão, na medida em que carrega características que náo estáo relacionadas com a qualidade do curso que se pretende avaliar.

O IDD é uma forma de mensurar o valor agregado. Grosso modo, ele procura comparar o desempenho dos estudantes concluintes de uma instituição em relação aos resultados obtidos pelas demais instituiçóes cujos perfis dos ingressantes sejam semelhantes. Para tanto, é preciso analisar o perfil dos ingressantes e concluintes do mesmo curso. Com base no desempenho dos alunos ingressantes é possível estimar qual seria o resultado esperado dos estudantes ao final do curso.

O cálculo efetivo do IDD nada mais é que a diferença do desempenho médio observado pelos concluintes de uma instituição e o desempenho esperado desses estudantes. Isto posto, cabe discutir como é estimado o desempenho esperado dos alunos concluintes. 
Os determinantes do desempenho médio dos estudantes concluintes de um curso $\left(\bar{C}_{i}\right)$ foram separados em três parcelas: 1) a primeira $\left(C_{i}^{I}\right)$ determinada pelo nível médio de formaçáo dos estudantes que ingressaram no curso $\left.\left(\bar{I}_{i}\right) ; 2\right)$ a segunda parcela $\left(D_{i}\right)$ determinada pela diferença da qualidade do curso em que o aluno está matriculado $\left(Q_{i}\right)$ e a qualidade média dos cursos $\left(\bar{Q}_{i}\right)$; e 3$)$ um distúrbio aleatório $\left(e_{i}\right)$. Vale ressaltar que o nível médio de formação dos estudantes que ingressaram no curso é utilizado por não haver informaçóes sobre as características de formação anterior ao curso para os alunos concluintes. Portanto, há a suposição implícita de que esta característica é semelhante entre os dois grupos de alunos para cada curso.

Formalmente temos:

$$
\begin{aligned}
& \bar{C}_{i}=C_{i}^{I}+D_{i}+e_{i} \text { (1), sendo } \\
& C_{i}^{I}=E\left[\bar{C}_{i} \mid \bar{I}_{i}\right] \mathrm{e} \\
& E\left[e_{i} \mid \bar{C}_{i}, D_{i}\right]=0 .
\end{aligned}
$$

A equação utilizada para a estimação de $\bar{C}_{i}$ :

$$
\bar{C}_{i}=\alpha+\beta \bar{P}_{i}+\gamma W_{i}+\delta Z_{i}+u_{i} \text { (2), onde }
$$

$\bar{C}_{i}$ : média ponderada das notas médias de conteúdo específico e de formação geral dos concluintes do curso " $i$ ";

$\bar{P}_{i}$ : média ponderada das notas médias de conteúdo específico e de formação geral dos ingressantes do curso " $i$ ";

$W_{i}$ : proporção de estudantes do curso " $\mathrm{i}$ ” cujos pais possuem nível superior; e

$Z_{i}$ : razão entre o número de concluintes e o número de ingressantes no curso "i”.

Pela equação (2) temos que:

$$
\begin{aligned}
& E\left[\bar{C}_{i} \mid \bar{I}_{i}\right]=\alpha+\beta \bar{P}_{i}+\gamma W_{i}+\delta Z_{i} ; \\
& u_{i}=D_{i}+e_{i} ; \mathrm{e} \\
& E\left[u_{i}\right]=0
\end{aligned}
$$

Assim, os resíduos da regressão geram uma estimativa da diferença entre o desempenho médio e o esperado dos concluintes de cada curso.

$$
\hat{D}_{i}=\bar{C}_{i}-\hat{C}_{i}^{I}
$$

Tendo sido exposto o método utilizado para estimar $D_{i}$, cabe fazer alguns comentários acerca de alguns procedimentos que foram adotados para minimizar a possibilidade de ocorrência de erros na estimação:

1. para o cálculo da nota média foram considerados apenas os estudantes que obtiveram notas positivas; 
2. cursos com menos de dez participantes, ou com taxa de participação inferior a $20 \%$ dos selecionados, foram excluídos da estimação.

A partir do valor estimado de $D_{i}$, dividindo-o pelo seu desvio padrão, obtêmse o seu valor padronizado $\left(D_{i}^{P A D}\right)$. Com o intuito de melhorar as estimativas, os indicadores fora do intervalo entre -3 e 3 foram excluídos da amostra. A partir daí, todo o processo é refeito para se obter o IDD de cada curso.

Complementarmente, é calculado o IDD conceito, segundo os critérios que seguem:

$$
Z_{i}=5 * \frac{I D D^{i}+\left|I D D_{I N F}^{i}\right|}{I D D_{S U P}^{I}+\left|I D D_{I N F}^{i}\right|} \text {, sendo }
$$

$Z_{i}$ : transformação do IDD para criação das faixas de conceito;

$\left|I D D_{I N F}^{i}\right|:$ módulo do menor IDD acima de -3 ; e

$I D D_{S U P}^{I}$ : maior IDD abaixo de 3.

Os conceitos foram definidos segundo exposto na tabela abaixo.

\section{Tabela 1 - Valores do IDD conceito}

\begin{tabular}{cc}
\hline IDD conceito & Valor de $\mathbf{Z}_{\mathbf{i}}$ \\
\hline 1 & 0,0 a 0,9 \\
2 & 1,0 a 1,9 \\
3 & 2,0 a 2,9 \\
4 & 3,0 a 3,9 \\
5 & 4,0 a 5,0 \\
\hline Fonte: Inep/MEC - Nota técnica do IDD.
\end{tabular}

\section{Metodologia para recálculo do IDD}

Como indicamos, a metodologia utilizada para analisar a potencial capacidade do Enem como baseline será o recálculo do IDD 2006, substituindo a nota do Enade dos alunos ingressantes pela nota do Enem 2005 desses mesmos alunos.

Este estudo foi possível devido à disponibilização dos microdados do Enade 2006 e do Enem 2005, juntamente com o CPF dos participantes nesses exames. Vale ressaltar que foi assinado um termo de compromisso para que náo houvesse divulgação de resultados em que o aluno pudesse ser identificado. Com o CPF dos participantes do Enade e do Enem foi possível identificar os alunos que fizeram o Enem em 2005 e que também participaram do Enade 2006.

Contudo, náo conseguimos identificar todos os alunos ingressantes que participaram do Enade 2006 no Enem 2005. Mesmo com a expansão do Enem entre

54 - Est. Aval. Educ., São Paulo, v. 21, n. 45, p. 45-66, jan./abr. 2010 
os alunos que estão terminando o ensino médio, é provável observarmos pessoas ingressando na universidade depois de alguns anos da conclusão do ensino médio; assim, essas pessoas apresentam menor probabilidade de realizar o Enem. Dentre os 276.750 alunos ingressantes que realizaram o Enade 2006, recuperamos no Enem 2005 um total de 78.797, o que representa $35,12 \%$ da amostra. A amostra completa, contendo os alunos ingressantes que participaram das duas avaliaçóes e os alunos concluintes que participaram do Enade, totalizou 291.022 indivíduos.

Uma vez que a nova amostra apresenta somente $35,12 \%$ dos ingressantes que participaram do Enade, optamos por recalcular o IDD de duas formas. Primeiramente, recalculamos o IDD da forma tradicional ${ }^{2}$, utilizando as notas do Enade dos ingressantes e dos concluintes. Em seguida, recalculamos o IDD com a nota do Enem dos ingressantes e com a nota do Enade dos concluintes. Ao recalcularmos o IDD da forma tradicional com a amostra reduzida, criamos um IDD que pode ser comparável com o IDD calculado a partir da nota do Enem. Vale ressaltar que nessas duas formas de cálculo foram utilizados os filtros mencionados na descrição da metodologia de cálculo do IDD.

Antes de prosseguirmos com o cálculo do IDD foi necessário agregarmos as informaçóes dos alunos por curso. O IDD 2006, divulgado pelo Inep, foi calculado para os seguintes cursos, avaliados pelo Enade em 2006: Administração, Arquivologia, Biblioteconomia, Biomedicina, Ciências Contábeis, Ciências Econômicas, Comunicação Social, Design, Direito, Música, Normal Superior, Psicologia, Secretariado Executivo, Teatro e Turismo.

As estimaçôes que geraram o cálculo do IDD foram realizadas separadamente, para cada um desses 15 cursos, pelo método de Mínimos Quadrados Ordinários (MQO). Primeiramente, calculamos o IDD pela metodologia tradicional com a estimação da equaçáo 3.

Enade_concl Eg $_{i g}=\beta_{0}+\beta_{1}$ Enade_ingres $_{i g}+\beta_{2}$ Escpai_sup $_{i g}+\beta_{3}$ conc $/$ ingr $r_{i g}+\varepsilon_{i g}$ (3)

Contudo, ao estimarmos esta equaçáo com a base reduzida, encontramos a possibilidades de viés de seleção relacionado com a escolha de prestar o Enem, dado o fato de o exame ter caráter voluntário. Esse viés ocorre, em razão do grupo de ingressantes

${ }^{1}$ Infelizmente, no questionário do Enade não há uma variável que identifique o ano de conclusão do ensino médio dos alunos, não permitindo que esse quantitativo seja calculado. ${ }^{2}$ Quando nos referimos ao cálculo do IDD da "forma tradicional", utilizamos a metodologia da nota técnica do IDD divulgada pelo Inep e descrita na subseção "O cálculo do IDD original”. Por essa metodologia, o cálculo baseia-se na nota do ingressante e do concluinte do Enade. 
que prestou o Enem apresentarem as melhores notas no Enade, comparativamente aos ingressantes que não prestaram o Enem, como podemos observar na tabela 2 .

Tabela 2 - Média do Enade dos ingressantes que prestaram ou não o Enem

\begin{tabular}{lcccc}
\hline & \multicolumn{2}{c}{ Amostral } & \multicolumn{2}{c}{ Expandido } \\
\cline { 2 - 5 } & $\begin{array}{c}\text { Prestou } \\
\text { Enem }\end{array}$ & $\begin{array}{c}\text { Não } \\
\text { prestou } \\
\text { Enem }\end{array}$ & $\begin{array}{c}\text { Prestou } \\
\text { Enem }\end{array}$ & $\begin{array}{c}\text { Não } \\
\text { prestou } \\
\text { Enem }\end{array}$ \\
\hline Média Nota Formação Geral do Enade & 40,13 & 32,43 & 46,86 & 43,10 \\
Média Nota Específica do Enade & 29,32 & 24,47 & 33,99 & 32,47 \\
Média Nota Geral do Enade & 33,42 & 27,57 & 38,95 & 36,71 \\
\hline Fonte: Elaboração própria com base nos microdados do Enade 2006 e do Enem 2005.
\end{tabular}

Para corrigimos esse viés de seleção, construímos uma variável ( $\operatorname{Pr}$ op) que representa o percentual de alunos, em cada curso, que prestou o Enem e o Enade, dentre o grupo de ingressantes. Assim, a equação 4 representa a re-estimação do modelo com a nota do ingressante e do concluinte do Enade com uma variável a mais, $\operatorname{Pr} o p$.

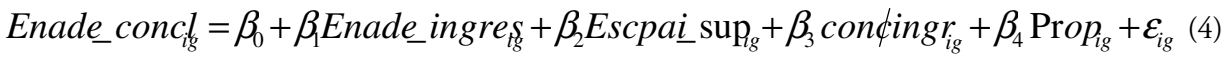

Além da variável $\operatorname{Pr} o p$, utilizamos igualmente as demais variáveis da estimação que originou o IDD tradicional. Como variável dependente, temos o "desempenho médio no Enade do concluinte" (Enade_concl). Já como variáveis explicativas, incluímos o "desempenho médio no Enade do ingressante" (Enade _ingres), o "percentual de ingressantes cujos pais têm nível superior" (Escpai_sup) e a "razão entre número de concluintes e o número de ingressantes" (conclingr). Por fim, o termo $\varepsilon_{\text {ig }}$ refere-se ao termo aleatório de erro. Vale a pena destacar que nossa unidade de análise (ig) representa o curso "i" da instituição "g”. Dessa forma, para facilitar a descrição dos resultados das estimações, utilizaremos o termo "curso" ou "cursos" para nos referimos à unidade de análise. As estimaçóes da equação 4 encontram-se na tabela 3 , e cada uma das colunas da tabela representa a estimação para um dos 15 cursos mencionados anteriormente.

Após efetuarmos a padronização do resíduo $(Y-\widehat{Y})$ da equação 4, observamos que alguns cursos apresentaram essa padronização abaixo de -3 ou acima de +3 . Por essa razão, optamos por re-estimar a equação 4 somente com os cursos que apresentaram seu resíduo padronizado no intervalo de $-3 \mathrm{a}+3^{3}$. Os resultados dessa estimação apresentam-se na tabela 4, sendo que os resultados de cada curso estáo representados por um número de 1 a 15, seguindo a ordem dos cursos listados anteriormente neste trabalho. 


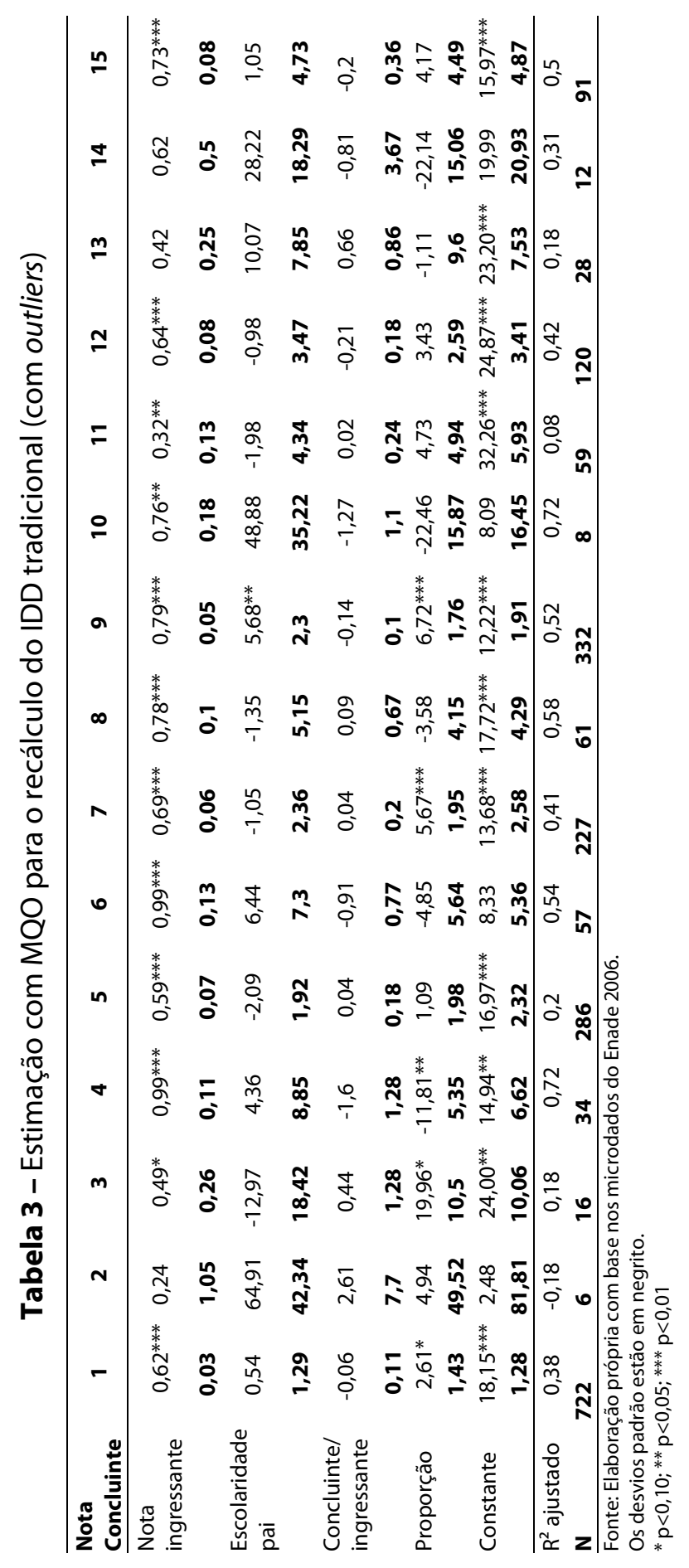

Est. Aval. Educ., São Paulo, v. 21, n. 45, 45-66, jan./abr. 2010 • 57 


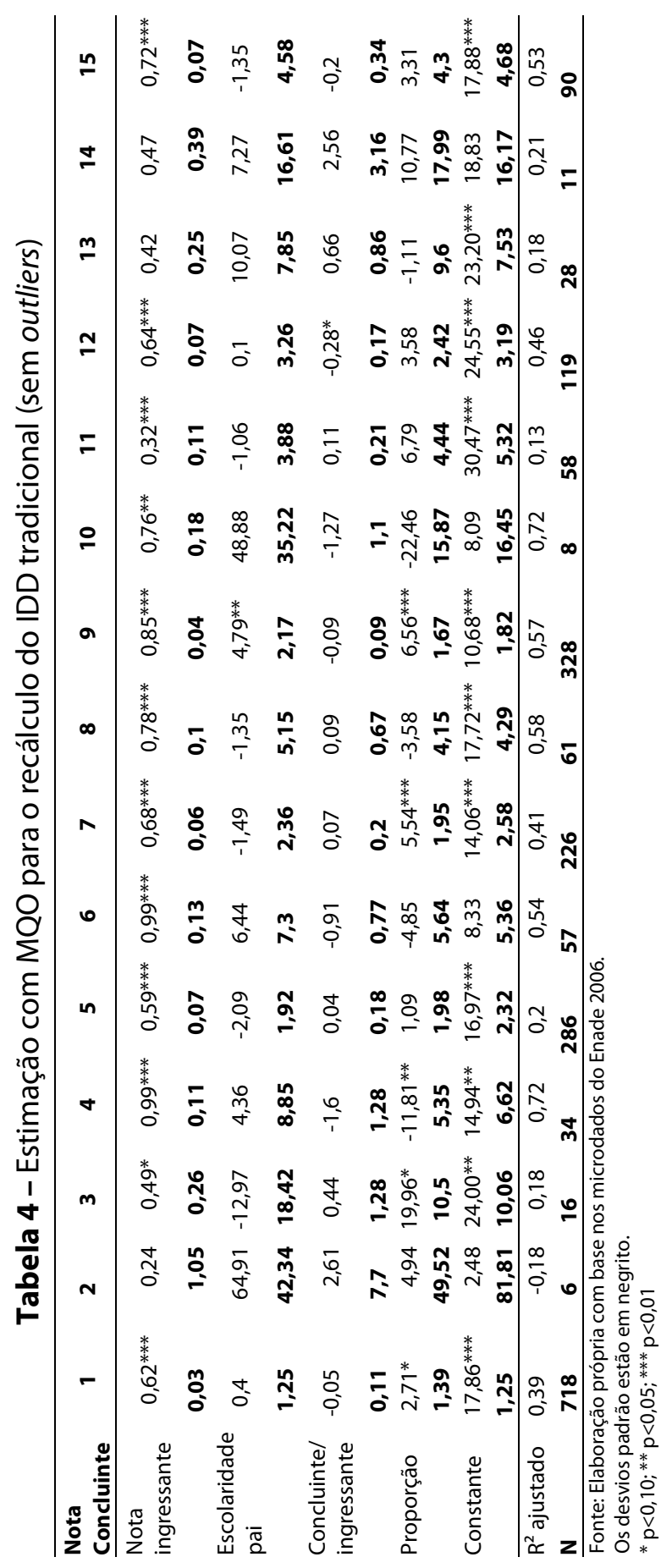

58 - Est. Aval. Educ., São Paulo, v. 21, n. 45, p. 45-66, jan./abr. 2010 
Ao compararmos essas duas estimaçóes (com e sem outliers), observamos que não ocorreram grandes modificaçóes nos coeficientes, nos erros padrão, no tamanho do $\mathrm{N}$ e no $\mathrm{R}^{2}$ ajustado. Além disso, para ambas as estimaçóes, a estatística $\mathrm{F}$ somente não foi estatisticamente significativa nas estimaçóes 2, 3 e 14, que representam os cursos de Arquivologia, Biblioteconomia e Teatro, respectivamente. Isso significa que a regressão como um todo não foi estatisticamente significativa. Provavelmente, esse resultado reflete o baixo número de observações (penúltima linha em negrito das tabelas 3 e 4) que essas estimaçóes apresentaram. Ademais, é possível observar que a nota do ingressante apresentou efeito positivo na nota do concluinte em todas as estimações. Por fim, o cálculo do IDD tradicional baseou-se nas estimações sem outliers (Tabela 4). Os resultados desse IDD serão comentados mais à frente, conjuntamente com os do IDD calculado com a nota do Enem do ingressante.

Nossa próxima etapa consiste em apresentar os resultados da estimação 4 que originou o IDD com a nota do Enem. A única diferença entre essa estimação e a estimação 5, apresentada a seguir, é que substituímos a variável "desempenho médio no Enade do ingressante" (Enade_ingres) por "desempenho médio no Enem dos ingressantes que prestaram Enade" (Enade_ingres):

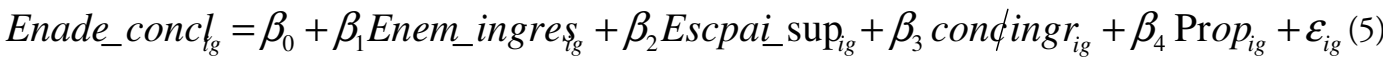

As notas consideradas para a variável Enem_ingres foram as notas da prova objetiva e da redaçáo. O peso atribuído para cada uma dessas provas para construir o desempenho médio no Enem foi de 0,5. As demais variáveis de controle e a variável dependente permaneceram as mesmas. Na tabela 5 encontram-se os resultados das estimaçóes com outliers.

Da mesma forma, após efetuarmos a padronização do resíduo $(Y-\bar{Y})$ da equaçáo 4 , observamos que alguns cursos apresentaram essa padronização fora do intervalo de $-3 \mathrm{a}+3$. Por essa razão, reestimamos a equaçáo 5 somente com os cursos que apresentaram seu resíduo padronizado dentro desse intervalo. Os resultados dessa estimação estão na tabela 6.

Ao compararmos as estimações das tabelas 5 e 6, nota-se que a amostra apresentou uma perda de 23 cursos (unidade de análise). No que diz respeito às principais estatísticas, elas não apresentaram grandes variações entre as estimaçóes. Em relação à estatística $F$, esta não foi estatisticamente significativa nas estimações 2, 3, 10, 11, 13 e 14, que representam os cursos de Arquivologia, Biblioteconomia, Música, Normal Superior, Secretariado Executivo e Teatro, respectivamente. Deve-se reconhecer que o dobro de cursos (dos 15 avaliados), comparativamente às estimaçóes das tabelas 3 e 4, apresentaram suas estimaçóes não significativas. Ademais, a nota do Enem do ingressante apresentou efeito positivo na nota do concluinte em todas as estimaçóes. Por fim, para calcularmos o Conceito IDD com o Enem, também utilizamos as estimações sem outliers. 


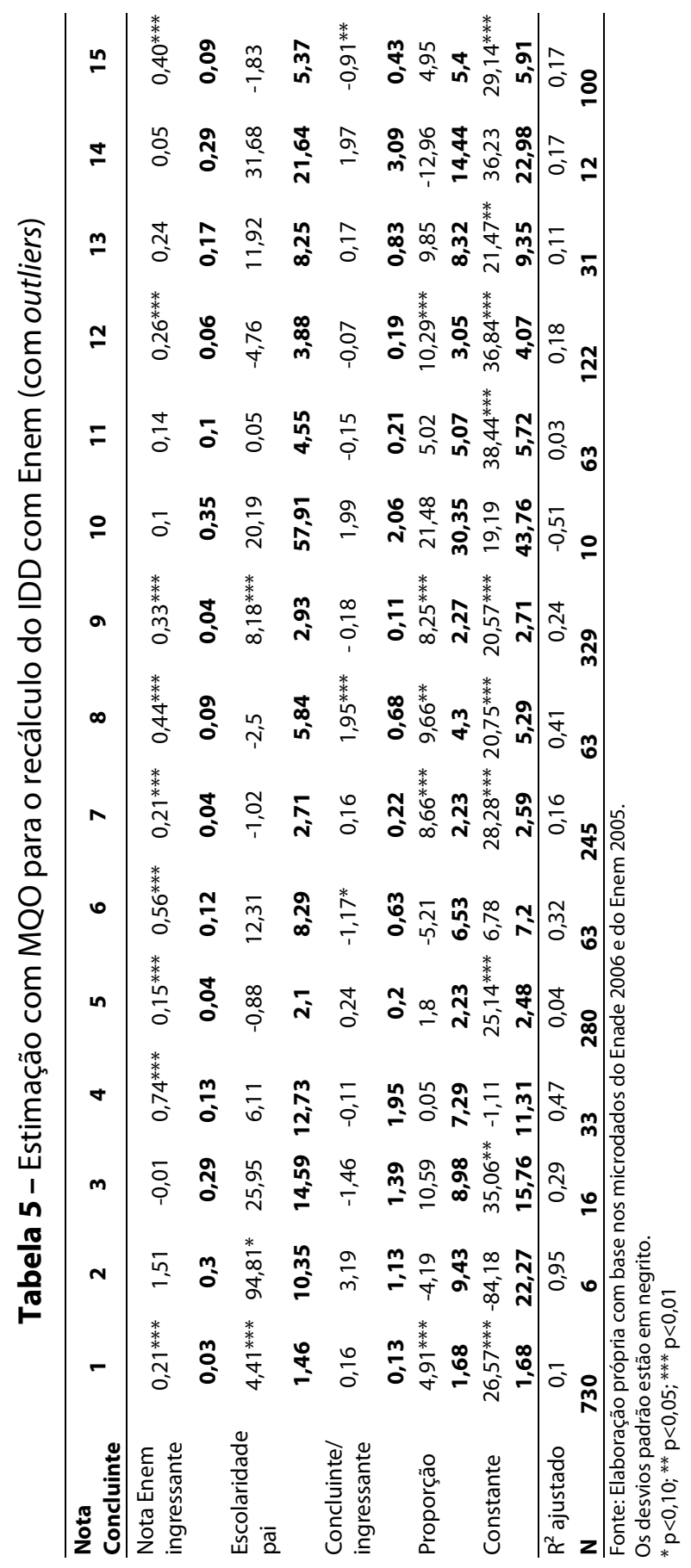

60 - Est. Aval. Educ., São Paulo, v. 21, n. 45, p. 45-66, jan./abr. 2010 


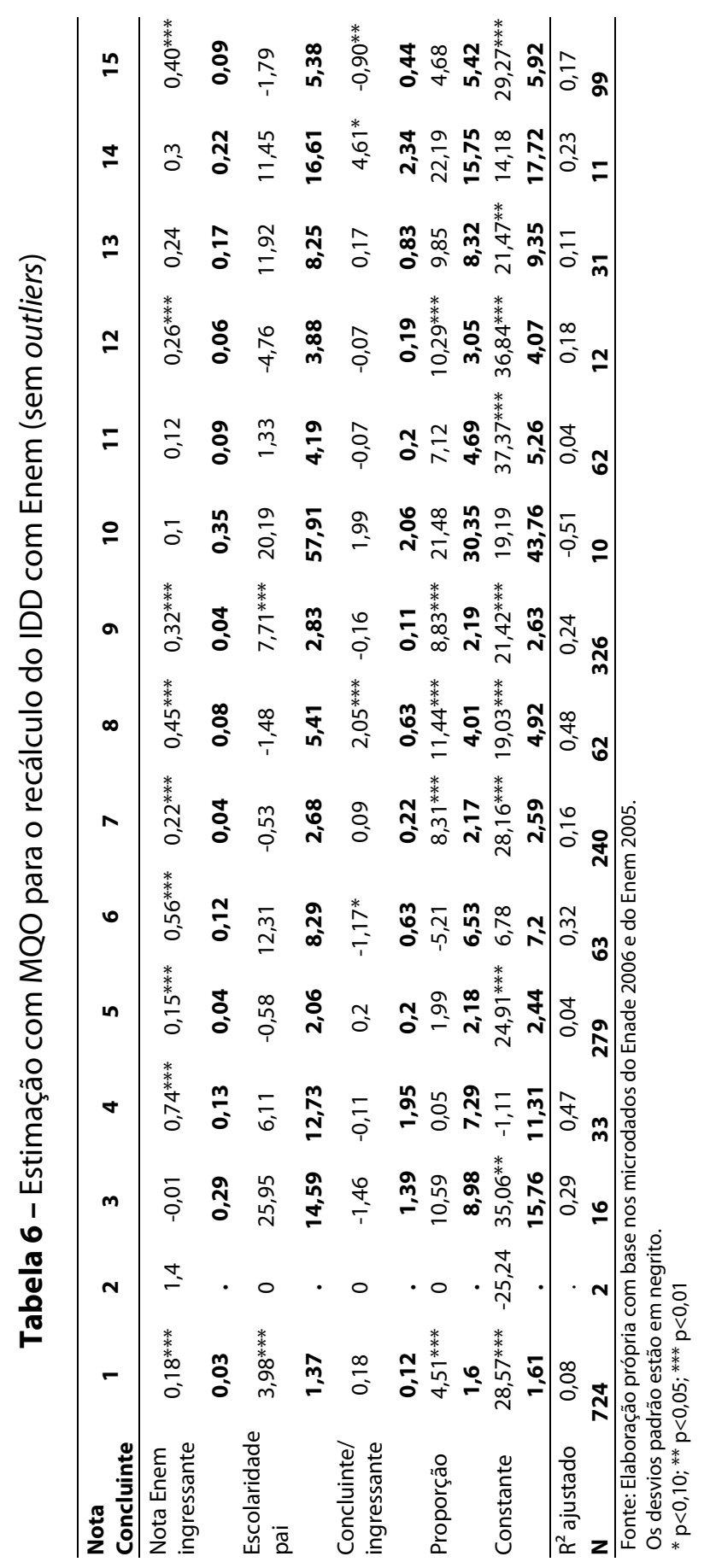

Est. Aval. Educ., São Paulo, v. 21, n. 45, 45-66, jan./abr. 2010 • 61 
$\mathrm{Na}$ tabela 7, realizamos alguns exercícios de correlaçôes entre o Conceito IDD tradicional e o Conceito IDD com o Enem. Assim, poderemos analisar a capacidade do Enem como alternativa ao Enade ingressante como baseline para o cálculo do valor agregado dos cursos por meio do IDD. Para isso calculamos correlaçôes simples e de ordem (Spearman).

Também na tabela 7 há uma segunda análise, a qual se refere à correlação entre os resíduos padronizados (estimação com as notas do Enade do ingressante e com as notas do Enem), antes de serem discretizados entre 1 e 5 (Conceito IDD).

Tabela 7 - Correlações entre o IDD tradicional e o IDD com Enem

\begin{tabular}{l|cc|cc}
\hline & \multicolumn{2}{|c|}{ Conceito IDD } & \multicolumn{2}{c}{ Resíduo Padronizado } \\
\cline { 2 - 5 } & $\begin{array}{c}\text { Correlação } \\
\text { Simples }\end{array}$ & $\begin{array}{c}\text { Correlação } \\
\text { de Spearman }\end{array}$ & $\begin{array}{c}\text { Correlação } \\
\text { Simples }\end{array}$ & $\begin{array}{c}\text { Correlação } \\
\text { de Spearman }\end{array}$ \\
\hline Geral & 0,71 & 0,68 & 0,79 & 0,73 \\
Administração & 0,65 & 0,58 & 0,79 & 0,73 \\
Arquivologia & - & - & - & - \\
Biblioteconomia & 0,13 & 0,12 & 0,35 & 0,33 \\
Biomedicina & 0,77 & 0,7 & 0,68 & 0,36 \\
Ciências Contábeis & 0,78 & 0,75 & 0,9 & 0,86 \\
Ciências Econômicas & 0,6 & 0,61 & 0,66 & 0,76 \\
Comunicação Social & 0,82 & 0,82 & 0,87 & 0,85 \\
Design & 0,8 & 0,78 & 0,84 & 0,8 \\
Direito & 0,63 & 0,64 & 0,69 & 0,69 \\
Música & 0,99 & 0,98 & 0,98 & 0,99 \\
Normal superior & 0,98 & 0,98 & 0,97 & 0,99 \\
Psicologia & 0,81 & 0,83 & 0,88 & 0,88 \\
Secretariado Executivo & 0,84 & 0,87 & 0,82 & 0,9 \\
Teatro & $-0,55$ & $-0,5$ & 0,82 & $-0,5$ \\
Turismo & 0,75 & 0,71 & 0,74 & 0,7 \\
\hline Fonte: Elaboração própria com base nos microdados do Enade 2006 e do Enem 2005 &
\end{tabular}

Na primeira análise, observamos que para a maioria dos cursos a correlação entre os Conceitos IDDs - o tradicional e o proposto - pode ser considerada alta: em média 0,75.

Até onde temos conhecimento, existe somente um trabalho empírico no Brasil que examina a correlação dos resultados de uma avaliação em relação a outra. Esse estudo foi realizado por Pansanato e Soares (1999), e trata da capacidade preditiva do Enem em relaçáo ao desempenho dos candidatos na $1^{\text {a }}$ fase do vestibular da

62 - Est. Aval. Educ., São Paulo, v. 21, n. 45, p. 45-66, jan./abr. 2010 
Universidade Federal de Minas Gerais (UFMG) de 1999. Os autores obtiveram uma correlaçáo de ordem de 0,79 entre os resultados do Enem e o desempenho dos alunos na $1^{\text {a }}$ fase do vestibular da UFMG - resultado considerado excelente pelos autores. Desse modo, é possível afirmar que as correlaçóes obtidas neste trabalho podem ser consideradas satisfatórias.

Adicionalmente, vale ressaltar que os cursos com maior número de observaçôes - Administração, Ciências Contábeis, Comunicação Social e Direito - apresentaram correlaçóes de ordem entre $60 \%$ e $80 \%$ entre o IDD tradicional e o IDD calculado com base na nota do Enem dos ingressantes. Por sua vez, os cursos que apresentaram as menores correlaçóes entre os IDDs foram Biblioteconomia e Teatro - cursos que estáo dentre aqueles com menor número de observaçôes. Além disso, observa-se que a diferença entre a correlação simples e a de ordem foi de no máximo 0,07 p.p (pontos percentuais).

O segundo exercício, o qual se refere à correlação entre os resíduos padronizados (coluna 3 e 4 da tabela 7), é importante porque ao calcularmos as correlaçóes com uma variável discreta (Conceito IDD da coluna 1 e 2 da tabela 7), podemos perder informaçóes, em razão da pouca variabilidade. Contudo, nota-se que em geral as correlaçóes entre os resíduos padronizados apresentam valores apenas um pouco superiores do que entre os do Conceito IDD.

\section{CONCLUSÃO}

Neste estudo, buscamos analisar a possibilidade de se utilizar os resultados do Enem, como alternativa aos resultados do Enade dos ingressantes, para o cálculo do IDD dos cursos - indicador de valor agregado utilizado atualmente. Ao calcularmos um novo IDD, substituindo a nota do Enade dos alunos ingressantes pela nota do Enem desses alunos, obtivemos correlaçóes entre esse novo IDD e o IDD calculado tradicionalmente de cerca de 0,75 .

Esses resultados apresentam indícios de que, além das vantagens em termos de eficácia do uso do Enem como baseline para o cálculo do valor agregado dos cursos, dados os incentivos para sua realização, bem como de eficiência, ao dispensar a aplicação do Enade para ingressantes, náo haveria uma mudança muito significativa na ordenação da nota dos indivíduos ao realizar essa substituição.

Algumas ressalvas devem ser feitas com relação a esses resultados. Em primeiro lugar, o resultado do presente trabalho leva em conta somente $35,12 \%$ dos ingressantes que prestaram o Enade em 2006, e que também prestaram o Enem em 2005, e que estes apresentaram nota no Enade superior àqueles que 
não prestaram Enem. Portanto, sugere-se que sejam realizadas novas análises com dados referentes a outros anos, permitindo a análise dos resultados dos cursos avaliados nesses outros anos e também a busca de um aumento no número de indivíduos que tenham realizado as duas avaliaçóes - ampliando, assim, o potencial de comparação entre elas.

Caso se confirmem os resultados desta análise, da mesma forma que o $\mathrm{Mi}$ nistério da Educação determinou a obrigatoriedade da participação dos alunos no Enade, condicionada à obtençáo do diploma, sugerimos que o MEC determine que a realização do Enem se torne obrigatória para qualquer aluno que deseje se matricular em uma instituição de ensino superior, independentemente se essa instituição utiliza o Enem em seu processo seletivo, ou não. Desse modo, a totalidade dos alunos do ensino superior realizaria o Enem, e essa nota serviria como substituta para a nota do Enade dos ingressantes. Assim, conseguiríamos, no longo prazo, utilizar no cálculo do IDD a nota do concluinte, juntamente com sua nota no Enem quando ingressou na IES $^{3}$, em vez da nota de outros ingressantes.

Primeiramente, há uma grande vantagem na adoção dessa política, pois isso geraria uma redução de custos para o Inep, uma vez que não ocorreria mais a aplicaçáo do Enade para os ingressantes nos cursos de graduação. Em segundo lugar, essa alteração geraria uma medida melhor da qualidade dos alunos ingressantes, em razáo de que esses teriam maiores incentivos ao realizar o Enem do que ao realizar o Enade, pois o Enem já é utilizado para o processo seletivo de diversas IES e para programas como o ProUni. Dessa forma, a nossa proposta, na verdade, é a ampliação de um procedimento que muitas IES públicas e privadas já adotam.

Por fim, vale ressaltar, ainda, que este processo deve ser realizado de forma cuidadosa, precedido de análises cuidadosas dos questionários socioeconômicos aplicados aos estudantes em ambos os exames, de forma a compatibilizar esses questionários e não correr o risco de perder informaçóes importantes a serem utilizadas nos processos de avaliação e regulação de cursos e em estudos que subsidiem as políticas educacionais brasileiras.

\footnotetext{
${ }^{3}$ Mesmo no longo prazo, utilizar a nota do Enade do aluno concluinte, quando este foi ingressante, é incerto, uma vez que o seu curso poderia não fazer parte do conjunto de cursos avaliados no período em que ingressou na IES. Além disso, mesmo que seu curso tenha sido avaliado, este concluinte poderia náo ter sido parte da amostra que prestou o Enade quando era ingressante.
}

64 • Est. Aval. Educ., São Paulo, v. 21, n. 45, p. 45-66, jan./abr. 2010 


\section{REFERÊNCIAS BIBLIOGRÁFICAS}

BRASIL. Ministério da Educação. Instituto Nacional de Estudos e Pesquisas Educacionais Anísio Teixeira. Resultado do indicadorde diferença entre os desempenhos esperado e observado IDD: Nota Técnica do IDD. Brasília: Inep, 2007.

BRASIL. Ministério da Educação. Proposta à Associação Nacional dos Dirigentes das Instituições Federais de Ensino Superior. Brasília: MEC/Assessoria de Comunicação, 2009.

HANUSHEK, E.; RAYMOND, M. The effect of school accountability systems on the level and distribution of student achievement. Journal of the European Economic Association, v. 2, n. 2/3, p. 406-415, 2004.
PANSANATO, K. A.; SOARES, J. F. Desempenho dos alunos no Enem e no vestibular da UFMG. In: JORNADA LATINO-AMERICANA DE ESTATÍSTICA APLICADA, 1. Anais... São Carlos, 1999.

REZENDE, M. The effects of accountability on higher education. In: ENCONTRO BRASILEIRO DE ECONOMETRIA, 30. Anais... Salvador, 2008.

VERHINE, R. E.; DANTAS, L. M. V.; SOARES, J. F. Do Provão ao Enade: uma análise comparativa dos exames nacionais utilizados no ensino superior Brasileiro. Ensaio: Avaliação e Políticas Públicas em Educação, Rio de Janeiro, v. 14, n. 52, p. 291-310, 2006.

Recebido em: setembro 2009

Aprovado para publicaçáo em: dezembro 2009 